Pakistan, almost certainly a conservative estimate. Every year many Pakistanis living in Britain take their children back to Pakistan on holiday. An increasing number of these children have been born here and are thus unlikely to have any naturally acquired immunity to poliomyelitis.

The live Sabin oral poliomyelitis vaccine is very safe and provides excellent protection against the disease. Three doses are given during the first 12 months of life followed by boosters during the first year at school, repeated between the ages of 15 and 19 or on leaving school. Further doses should also be given before travel to southern European and subtropical or tropical countries. This is as important for adults as for children-poliomyelitis in adult life has a high morbidity and mortality. ${ }^{2}$

Recent adverse publicity directed principally against whooping cough immunization has contributed towards a fall in the number of children immunized against infectious diseases, including poliomyelitis. Many infants entering school in Britain are not nowadays fully protected against this infection (formerly known as infantile paralysis), and about $20 \%$ of all school children have not been immunized against it at all. ${ }^{3}$ Young parents today have no personal knowledge of the disease-or indeed of other infections such as diphtheriaand do not require much adverse publicity to discourage them from having their children immunized. In 1974 there was a statistically significant increase in whooping cough notifications, probably resulting from the declining incidence of immunization against this infection. It is possible that poliomyelitis might become commoner in a similar way. Two factors important in this context are a susceptible population and ready access to areas of the world where the disease is still prevalent. The W.H.O. surveillance programme may help to reduce the incidence of poliomyelitis in these areas, but it will be many years before it disappears completely. Until then we must continue to encourage immunization against the disease. The present situation where approximately $80 \%$ of children in Britain are immunized may be sufficient to prevent an extensive outbreak of poliomyelitis but any reduction in this figure could have serious consequences.

Finally, for epidemiological as well as diagnostic reasons, viral studies should be carried out in all patients with apparent virus infections of the nervous system, as poliomyelitis can present with several clinical syndromes, including aseptic meningitis or encephalitis without paralysis. Specimens of stool and cerebrospinal fluid must be collected for virus culture from these patients, who should be admitted to an isolation unit.

\footnotetext{
1 World Health Organization, Weekly Epidemiological Record, 1974, 49, 389. 2 Banatvala, J. E., and Spencer, G. T., British Medical fournal, 1975, 1, 148.

* British Medical fournal, 1974, 3, 583.
}

\section{Unwanted Chemicals in Food}

Britons tend to be ambivalent in their attitudes to food additives. They expect to be able to buy foods of all kinds throughout the year, irrespective of breeding and harvest times; and at the same time they expect foods to be cheap and of standard appearance and consistency. On the other hand (led a little in their thinking by a vociferous few) they claim that they miss the old days when foods were fresh and they complain that frozen foods taste of nothing.
Of course prices can be kept down by prolonging the shelflife of products and by the bulk-marketing of foodstuffs. It is also easy to understand that people with low incomes may be unable to spend more than a bare minimum on food. But an attitude of mind which determines priorities in living is also an important factor. Britons in general, as distinct from Frenchmen, eat to live rather than vice versa. They leave the education of their tastebuds and the daily fulfilment of their olfactory senses to the mercies of competing food manufacturers. Dr. Johnson would not have approved! Some poeple, he wrote, have a foolish way of not minding, or pretending not to mind, what they eat. He minded his belly very studiously, and very carefully.

Each developed country has committees, consisting usually of independent scientists, which advise the government of the likely safety of or possible hazard from particular chemicals added to food, from food manufacturing processes, and from chemicals which may occur as residues in foods as a result of agricultural use of fertilizers, herbicides, and pesticides. Toxicological data derived from chemical and biological studies are carefully considered before new chemicals are introduced, and the safety of chemicals already in use is periodically reviewed as new test methods yield further data. The unfortunate members of such committees scrutinize mountains of data, discuss difficulties with the toxicologists responsible for designing and carrying out tests, ask for further studies to be carried out, and, where they think it necessary, recommend complete or partial restrictions on the use of particular chemicals or processes.

In 1955 a joint meeting of the Food and Agricultural Organization of the United Nations and the World Health Organization began the vetting of food additives for safety at the international level. ${ }^{1}$ Since then a joint F.A.O./W.H.O. Expert Committee has met 18 times to consider the safety of food additives. In the case of chemicals suitable for use in food an acceptable daily intake (A.D.I.) has to be determined for each substance. This is usually calculated as a fraction (such as 1/100th) of the level found to be without toxic effect in the species of animal most susceptible to its toxic activity. The latest joint meeting of this kind took place in Rome in June 1974, when for the first time the report recommended that A.D.I.s should take into account not only the amounts of chemicals added to food but also the amounts of the same chemicals that may be present naturally in food. This principle did not lead to any changes in the A.D.I.s for ascorbic acid or benzoic acid, but the committee was uneasy about nitrates: the amount occurring naturally in food and water may bring the total intake up to levels well above the recommended level for added nitrates. In view of the risk that carcinogenic nitrosamines may be formed by the interaction of nitrates with secondary amines the committee recommended that the matter should be the subject of an early review.

Modern marketing and advertising have conditioned people to judge edibility on the basis of colour. As a general principle regulatory committees permit the addition of chemicals-even seemingly harmless chemicals-only if a need to use them has been established. Most of the colours added to food are without nutritive value; their function is to make food look attractive and therefore worth buying. The 1974 F.A.O./ W.H.O. meeting considered 29 food colours. For only 6 of these were there sufficient chemical and biological data for A.D.I.s to be established. Temporary A.D.I.s, pending provision of more data, were given to a further 9 colours. No A.D.I. was given to 10 colours, and previously given A.D.I.s were withdrawn from 4 other colours because data requested 
earlier had not been made available or for other reasons. Clearly this is a highly unsatisfactory state of affairs-several of the colours for which no A.D.I.s were given are still being used in food.

Some addition of chemicals to food to preserve it and to enable it to be distributed in suitable processed forms is unavoidable. But only a fine line separates the use of chemicals for these reasons and the unnecessary adulteration of food for no reason other than profit. Laboratory tests and regulatory committees go a long way to ensuring that we come to no harm from chemicals added to food, but no system of safeguards merits absolute confidence, and if we mind our bellies very studiously and very carefully we will eschew all unnecessary adulteration of food. We can make a start by eliminating synthetic food colours.

1 General Principles Governing the Use of Food Additives-First Report. W.H.O. Technical Report Series, No. 129, 1957.

${ }^{2}$ Evaluation of Certain Food Additives: 18th Report of foint F.A.O./W.H.O. Expert Committee on Food Additives. W.H.O. Technical Report Series Expert Committee
No. 557, 1974.

\section{Home Therapy for Haemophilia}

More than $90 \%$ of the haemorrhages suffered by severely affected haemophiliacs affect their joints and muscles. These haemorrhages may occur at intervals of a month or so-in some cases several times a week-and in addition to causing extreme pain and distress at the time of bleeding can eventually lead to severe joint and muscle damage and permanent crippling. Furthermore, the frequent journeys to and from hospital for treatment result in repeated disruption of the liferoutine of both the patient and his family.

If antihaemophilic factor is given by intravenous injection as soon as possible after the onset of bleeding it rapidly controls haemorrhage and relieves pain; this striking effect has led to the introduction of home therapy for haemophilia. ${ }^{1-5}$ So far, the administration of antihaemophilic factor at home is proving to be both feasible and remarkably free from problems. In their recent study of 45 patients on home therapy, Levine and Britten ${ }^{4}$ found no morbidity attributable to the treatment, and the only important hazard reported was the exposure of family members to hepatitis from contaminated needles: one such case occurred in their group.

The purpose of home therapy is to try to minimize the effects of joint and muscle haemorrhages on the patient's daily work and activities and to reduce the incidence of long-term crippling. Patients are told, however, that if a haemorrhage is large or dangerous, particularly into a site such as the abdomen or neck; or if it comes from a large wound; or if headache develops especially after head injury, they should telephone their haemophilia centre as soon as possible and seek advice. Usually in such cases the patient will be asked to go to his centre, having first received a dose at home to protect him from the effects of the journey.

The criteria for putting a patient on home therapy vary slightly from centre to centre, but at present it is generally agreed that he should be severely affected, should not have antibodies to factor VIII, should have good veins, and should have a competent relative who can give the transfusions if the patient is not to transfuse himself. In an older patient with difficult veins it may be justified, though rarely, to establish an arteriovenous fistula at the wrist in order to have a readily accessible vascular channel and so allow the patient the benefits of home therapy. Sussman and Lozman ${ }^{6}$ have recently described such a procedure in one of their patients; after the operation the patient was able to carry out his own intravenous therapy at home without complications.

Freeze-dried antihaemophilic factor is the material of choice for home treatment, ${ }^{7}$ since it is stable on storage, easily reconstituted, and rarely causes reactions. Its potency is such that an effective dose can be given in small volumes, making it possible to give the dose by injection with a syringe. Unfortunately, freeze-dried antihaemophilic factor produced by the N.H.S. is still in short supply, and as a result some centres are being forced to use cryoprecipitate, which is not an ideal material for home therapy, whilst others have to buy antihaemophilic factor from commercial sources. The commercial preparations available in Britain are very good but expensiveat $10-12 p$ per unit of factor VIII a single dose for a small haemarthrosis may cost $£ 25-30$.

The cost of embarking on large-scale home-therapy programmes is understandably causing some concern, especially since it is not yet clear whether home therapy will lead to an increase or a decrease in usage of antihaemophilic factor. Rabiner and Telfer ${ }^{1}$ have reported an increased consumption by patients going on home therapy, but Levine and Britten ${ }^{4}$ and Le Quesne and her colleagues ${ }^{5}$ found no evidence of increased use in their patients. Furthermore even if experience shows that home therapy results in an increase in consumption of antihaemophilic factor, it may very reasonably be argued that the patients had been inadequately treated before starting home therapy and that such an increase would be justified. In addition, the benefits of home therapy are not limited only to the patient; the beneficial effect on the family of removing anxiety, tension, and frustration is very striking and is a welcome bonus.

${ }^{1}$ Rabiner, S. F., and Telfer, M. C., New England fournal of Medicine, 1970, 283, 1011 .

2 Rabiner, S. F., Telfer, M. E., and Fajardo, R., fournal of the American Medical Association, 1972, 221, 885 .

3 Bellingham, A., et al., British Medical fournal, 1967, 4, 531.

4 Levine, P. H., and Britten, A. F. H., Annals of Internal Medicine, 1973, $78,195$.

5 Le Quesne, Barbara, et al., Lancet, 1974, 2, 507.

Sussman, L. N., and Lozman, H., Fournal of the American Medical Association, 1974, 230, 437.

${ }^{7}$ Medical Research Council's Blood Transfusion Research Committee Working Party, British fournal of Haematology, 1974, 27, 391.

\section{Megacolon}

Megacolon may be defined as a state in which the bowel is persistently dilated and often thick-walled, and is associated with long-standing constipation. Constipation, in this context, implies infrequent and incomplete passage of faeces per rectum.

Patients with megacolon can be broadly divided into two main groups according to whether or not ganglia are present in the intermuscular plane of the rectal wall. Their complete absence, even along a short segment of rectum, denotes Hirschsprung's disease. If ganglia are present the megacolon may be secondary to some predisposing factor such as a stricture, a congenital anorectal abnormality, Chagas's disease, or a corda equina lesion; or there may be no obvious organic reason why the bowel should be so dilated. This latter group is often termed "idiopathic" and it accounted for $60 \%$ 